\title{
Sorption of Water by Bisphenol-A Polycarbonate and Polyoxyethylene Multiblock Copolymers with Varying Composition and Block Length
}

\author{
Toshitake Suzuki, ${ }^{*}$ Hiroshi ChiHARA, and Tadao KotakA** \\ Department of Macromolecular Science, Faculty of Science, \\ Osaka University, Toyonaka, Osaka 560, Japan
}

(Received September 21, 1983)

\begin{abstract}
For $(\mathrm{AB})_{n}$ type multiblock copolymers of bisphenol A polycarbonate (PC) and polyoxyethylene (POE) with varying composition and block length, water sorption behavior was examined at $25^{\circ} \mathrm{C}$. Copolymer samples with high PC content exhibited BET type IV isotherms and non-Fickian kinetics. Such behavior resembled that of PC homopolymers, presumably because the samples had a PC rich continuous phase. Copolymers with intermediate PC content showed sorption behavior varying with block length. Those with relatively long POE blocks exhibited BET type II isotherms and Fickian kinetics, and those with short blocks, BET type III isotherms but non-Fickian kinetics. Samples with low PC content exhibited BET type II isotherms and Fickian kinetics. This latter behavior was not found either in PC or POE homopolymers, and was specific to the POE rich multiblock copolymers, reflecting their microphase-separated structures and PC and POE intermixing phases.

KEY WORDS Block Copolymer / Multiblock Copolymer / Bisphenol-A Polycarbonate / Polyoxyethylene / Water Sorption / Sorption Isotherm / Sorption Kinetics / Diffusion Coefficient /
\end{abstract}

The sorption of small molecules by polymers has long been a fundamental problem attracting interest in polymer physical chemistry. Much research has been carried out on a variety of polymers and small molecules including gases, organic solvents and water. ${ }^{1-4}$ Earlier studies on this problem have been summarized in an excellent book edited by Crank and Park. $^{2}$ Among the polymer/ diffusant systems studied so far, polymer/ water systems are of particular interest. ${ }^{5-9}$ Since water molecules are relatively small but tend to associate with each other or with polar groups and impurities in the diffusing matrix, their diffusion behavior should be quite different from that of most of small molecules such as common organic solvents.

It is well-known that the diffusion coefficient D of an organic solvent for a polymer usually increases with solvent concentration, ${ }^{1}$ while the $\mathrm{D}$ of water either decreases or increases with the water concentration $\mathrm{C}$, depending on the type of polymer/water systems under consideration. ${ }^{5}$ For example, polymers with hydrophilic groups such as wool, ${ }^{10}$ nylon, ${ }^{11,12}$ and poly(vinyl alcohol), ${ }^{13}$ sorbed water molecules have been reported to bind first with polymers and that D increases with $\mathrm{C}$. But in the case of less hydrophilic polymers, clustering or self-association of sorbed water molecules takes place, and D decreases with C. ${ }^{5,6}$

Recently, interest ${ }^{14}$ has been directed to-

* Present address: Kanzaki Paper Manufacturing Co., Amagasaki, Hyogo 660, Japan.

** To whom all correspondence should be addressed. 
ward the sorption of small molecules by multicomponent and multiphase polymers often referred to as polymer alloys ${ }^{15-17}$; these include block and graft copolymers and polymer blends. For such heterophase systems, sorption should be quite complicated, since the behavior of sorbed molecules differs according to the phase and phase boundary region. Thus, water sorption in a heterophase system containing hydrophilic and hydrophobic microdomains should be strongly influenced by the multiphase structure of the system.

We synthesized ${ }^{18,19}$ three series of randomly coupled multiblock copolymers of bisphenolA polycarbonate (PC) and polyoxyethylene (POE) by a method proposed by Goldberg, ${ }^{20}$ and studied their thermal, mechanical and dielectric properties in detail. ${ }^{18,19}$ Since PC segments are hydrophobic and POE segments hydrophilic, we expected that PC-POE multiblock copolymers exhibit unique water sorption behavior depending on the PC/POE ratio and block length. An attempt was thus made to confirm this expectation, using two series of PC-POE copolymer samples (series II $^{18}$ and III $^{19}$ ) from our previous studies. The main results obtained are presented in this paper.

\section{EXPERIMENTAL}

\section{Materials}

The copolymer samples used were prepared by the condensation of bisphenol-A (B) and ethylene oxide (E) oligomers with phosgene, using the method of Goldberg. ${ }^{20}$ The details are given in our previous papers. ${ }^{18,19}$ Product composition was determined by elemental analysis and UV absorption. Average molecular weights were estimated on a gel permeation chromatograph (GPC; Toyo Soda Mfg. Co., HLC 801-A) equipped with a refractometer, a UV absorption monitor, and a small-angle laser-light scattering monitor (Toyo Soda Mfg. Co., LS-8). The elution solvent was tetrahydrofuran (THF). Narrow distribution poly-
Table I. Characteristics of copolymer samples ${ }^{\mathrm{a}}$

\begin{tabular}{|c|c|c|c|c|c|}
\hline \multirow[t]{2}{*}{$\begin{array}{l}\text { Sample } \\
\text { code } \\
\text { (BXEY) }\end{array}$} & $\begin{array}{l}\text { Bisphenol A } \\
\text { content in } \\
\text { monomer } \\
\text { feed }\end{array}$ & $\begin{array}{c}\text { Bisphenol A } \\
\text { Carbonate } \\
\text { content }\end{array}$ & $X$ & $Y$ & $Z$ \\
\hline & $w t \%$ & $w t \%$ & & & \\
\hline
\end{tabular}

Series II samples:

$\begin{array}{llrrrrr}\text { B50E182 } & 62.6 & 61.4 & 51.4 & 182 & 1.0 & 2 \\ \text { B18E68 } & 62.5 & 60.7 & 19.3 & 68 & 1.1 & 2 \\ \text { B7E23 } & 62.5 & 64.3 & 8.4 & 23 & 1.1 & 3 \\ \text { B5E14 } & 61.3 & 67.5 & 6.5 & 14 & 1.2 & 12 \\ \text { B3E9 } & 62.5 & 65.4 & 4.3 & 9 & 1.3 & 16 \\ \text { B2E4 } & 62.5 & 66.9 & 2.7 & 4 & 1.6 & 25\end{array}$

Series III samples:

\begin{tabular}{lrrrrrr} 
B22E46 & 75.0 & 73.1 & 22.9 & 46 & 1.1 & 12 \\
B9E14 & 75.1 & 77.2 & 9.6 & 14 & 1.1 & 21 \\
B13E68 & 53.5 & 51.8 & 13.9 & 68 & 1.1 & 9 \\
B5E23 & 52.7 & 52.3 & 5.5 & 23 & 1.2 & 37 \\
B5E68 & 31.1 & 30.0 & 6.1 & 68 & 1.2 & 11 \\
B2E23 & 31.3 & 30.0 & 2.8 & 23 & 1.6 & 35 \\
\hline
\end{tabular}

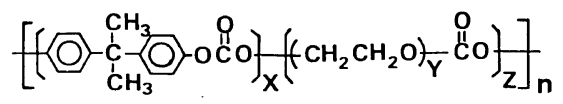

styrenes (Toyo Soda, TSK PS's) were used as the elution standard.

Table I summarizes the characteristics of the samples in this study. In the table, the samples are coded by BXEY, where $X$ and $Y$ denote the average degree of polymerization of PC blocks and POE precursors, respectively. The value of $X$ and average number $Z$ of the POE precursors coupled to form a single POE block were estimated from the monomer-feed and product composition data, assuming a random coupling of B units with POE precursors. For the series II samples, the $\mathrm{PC} / \mathrm{POE}$ ratio was about $63 / 37$ by weight, and $X$ varied from 2 to 50, and $Y$ from 4 to 182 (or $Y Z$ from 6.4 to 182). ${ }^{18}$ For the series III samples, the $P C / P O E$ ratio was about $75 / 25,50 / 50$, and $25 / 75$, and for each ratio two samples were prepared: one with long blocks and the other with short blocks.

The series II samples were moulded into films 0.25 to $0.30 \mathrm{~mm}$ thick by a laboratory hot press, above their respective softening tem- 
Table II. Overall and amorphous POE content and BET parameters from sorption isotherms at $\mathrm{RH}=32 \%$ and $25^{\circ} \mathrm{C}$

\begin{tabular}{|c|c|c|c|}
\hline \multirow{2}{*}{$\begin{array}{l}\text { Sample } \\
\text { code }\end{array}$} & $\begin{array}{c}\text { POE } \\
\text { content }\end{array}$ & $\begin{array}{l}\text { Amorphous } \\
\text { POE content }\end{array}$ & \multirow{2}{*}{$\begin{array}{c}K \\
\mathrm{mg} / \mathrm{g} \text { polymer }\end{array}$} \\
\hline & $\mathrm{wt} \%$ & $\mathrm{wt} \%$ & \\
\hline
\end{tabular}

Series II samples:

\begin{tabular}{lrrrr} 
B50E182 & 38.6 & 30.1 & 1.13 & 10.34 \\
B18E68 & 34.3 & 31.8 & 1.33 & 9.63 \\
B7E23 & 35.7 & 35.0 & 3.57 & 8.53 \\
B5E14 & 32.5 & 32.5 & 2.35 & 6.02 \\
B3E9 & 34.6 & 34.6 & 2.23 & 4.82 \\
B2E4 & 33.1 & 33.1 & 2.87 & 3.32 \\
Series III samples: & & & \\
B22E46 & 26.9 & 26.9 & 2.05 & 3.64 \\
B9E14 & 22.8 & 22.8 & 1.94 & 3.05 \\
B13E68 & 48.2 & 37.6 & 1.38 & 10.10 \\
B5E23 & 47.7 & 47.7 & 1.56 & 7.79 \\
B5E68 & 70.0 & 36.4 & 1.60 & 8.82 \\
B2E23 & 70.0 & 58.8 & 1.31 & 10.14 \\
\hline
\end{tabular}

a Estimated from the data for the degree of crystallinity of the POE phase given in ref. 18 and 19.

peratures ranging from 100 to $200^{\circ} \mathrm{C}$. The series III samples were cast from about $5 \mathrm{wt} \%$ chloroform solutions at room temperature. These films were dried in air for 3 to 4 days, then, at $10^{-2}$ torr for 2 more days, and annealed overnight at $60^{\circ} \mathrm{C}$ before each absorption experiment. For comparison, homopolymer films were prepared also by compression moulding. The POE homopolymer used was a commercial sample (Polyox WSRN-85, Union Carbide Corp.) with a nominal molecular weight of $2 \times 10^{5}$, obtained through the courtesy of Prof. G. C. Berry, Carnegie-Mellon University. The PC sample was an impurityfree experimental sample provided by Dr. Y. Murakami, Teijin Co., Ltd. Its molecular weight was estimated to be $6.2 \times 10^{4}$ by GPC with narrow molecular weight distribution PS as the elution standard.

For the structural characterization of the annealed specimens, their degree of crystallinity was determined by differential scanning calorimetry (DSC). ${ }^{18,19}$ The experiments were carried out on a DSC (Rigakudenki Co., Model 8055) in the range from 170 to $573 \mathrm{~K}$ at a heating rate of $10 \mathrm{~K} \mathrm{~mol}^{-1}$. Table II lists the results in terms of amorphous POE content (in $\mathrm{wt} \%$ of the whole specimen).

\section{Methods}

Sorption isotherms were determined by measuring the equilibrium amounts of absorbed water and water regains in $\mathrm{mg}$ water/g polymer with a Sartorius semimicrobalance accurate to $\pm 0.1 \mathrm{mg}$. In each case, a preweighed amount of specimen about 200 to $500 \mathrm{mg}$ was equilibrated at $25^{\circ} \mathrm{C}$ above one of the saturated salt solutions with the relative humidity $(\mathrm{RH})$ at $25^{\circ} \mathrm{C}$ ranging from 11.30 to $84.34 \%{ }^{21}$ The weight increase in the film was measured every $24 \mathrm{~h}$ until the weight became constant.

By this method, the equilibrium water regains were determined with an accuracy better than $5 \%$. However, for the samples with low POE content and/or at low relative humidity, the accuracy was rather poor. For such systems, we employed a Cahn RG automatic electrobalance (Cahn Instrument Co., Paramount, CA) with an accuracy of $\pm 0.005 \mathrm{mg}$ and an apparatus described below; the error involved in the measurement of equilibrium water regain on the least water absorbing sample was estimated to be less than $10 \%$.

Absorption and desorption rates were determined by weighing with the Cahn RG automatic electrobalance. Figure 1 schematically shows the appratus, which was operated in a thermostated room at $25 \pm 0.5^{\circ} \mathrm{C}$. The balance was placed in a Cahn vacuum bottle sealed with Apiezon grease. The temperature of the sample cell was regulated at a desired temperature within $\pm 0.05^{\circ} \mathrm{C}$ by circulating thermostated water through the jacket of the cell. The temperature of the salt solution reservoir was also regulated at $25.00 \pm 0.05^{\circ} \mathrm{C}$ by a thermostated bath. All other components of the apparatus including the vapor reservoir 


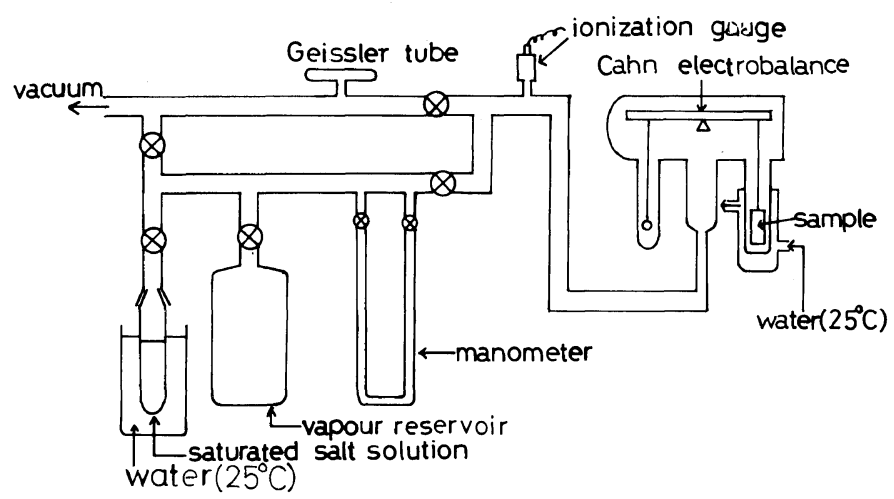

Figure 1. Schematic diagram of the Cahn Electrobalance system for measuring water sorption kinetics.

and the balance itself were kept at a temperature slightly above $25.0^{\circ} \mathrm{C}$ in order to prevent moisture condensation.

All sorption experiments were made with films about 100 to $300 \mathrm{mg}$ in dry weight and about 0.25 to $0.30 \mathrm{~mm}$ in thickness. Before each measurement, the film was dried at about $60^{\circ} \mathrm{C}$ in the Cahn vacuum bottle $\left(10^{-4}\right.$ torr $)$ to a constant weight (it usually took several hours) and further annealed in situ overnight. The cell temperature was then brought down to $25.00 \pm 0.05^{\circ} \mathrm{C}$, and the water vapor above the saturated salt solution was admitted into the sample cell. The weight increase in the film was followed until equilibrium was reached. The desorption rate was measured by evacuating the cell immediately after attainment of absorption equilibrium. The absorption and desorption measurements were made at three different humidities, $\mathrm{RH}=11.30$ (2.684 torr), 32.78 (7.787 torr), and 52.89\% (12.56 torr). The change in vapor pressure during each run was less than \pm 0.1 torr.

\section{Analysis of Sorption Kinetics Datá}

The absorption and desorption rate data were plotted ${ }^{1-3}$ as $M_{\mathrm{t}} / M_{\infty} v s .\left(t / l^{2}\right)^{1 / 2}$, where $M_{\mathrm{t}}$ is the amount of water absorbed by or desorbed from the film in a time $t, M_{\infty}$, the equilibrium amount of water absorbed, and $l$, the thickness of the dry film. If the sorption is governed by Fick's law, the value of $D$ can be calculated from the initial slope $R$ of the reduced sorption curve $\left[M_{\mathrm{t}} / M_{\infty} v s .\left(t / l^{2}\right)^{1 / 2}\right]$ by

$$
D=(\pi / 16) R^{2}
$$

However, for many diffusant/polymer systems, $D$ depends on the diffusant concentration $C .^{2,3}$ The $D$ defined by eq 1 is a certain mean value $\bar{D}$ of the variable diffusion coefficient over the range of $C$ covered by a particular run. For concentration-dependent systems, the values of $\bar{D}$ from the reduced absorption and desorption curves usually do not agree, ${ }^{2,3}$ and may be related approximately to the concentration dependent diffusion coefficient $D(C)$ by

$$
D=(1 / 2)\left(\bar{D}_{\mathrm{a}}+\bar{D}_{\mathrm{d}}\right)=C_{\infty}{ }^{-1} \int_{0}^{C_{\infty}} D(C) \mathrm{d} C
$$

where $D_{\mathrm{a}}$ and $D_{\mathrm{d}}$ are the apparent diffusion coefficients determined by eq 1 from the absorption and desorption curves, respectively, and $C_{\infty}$, the equilibrium concentration of the diffusant. According to eq 2, $D(C)$ may be determined by graphical differentiation of a $\bar{D} C_{\infty}$ $v s . \mathrm{C}_{\infty}$ curve. More accurate methods of estimating $D(C)$ have been proposed by various authors, ${ }^{3}$ but the above-mentioned method was used here.

\section{RESULTS}

\section{Sorption Isotherms}

Figures 2 and 3, respectively, show the equilibrium sorption isotherms at $25.0^{\circ} \mathrm{C}$ for 


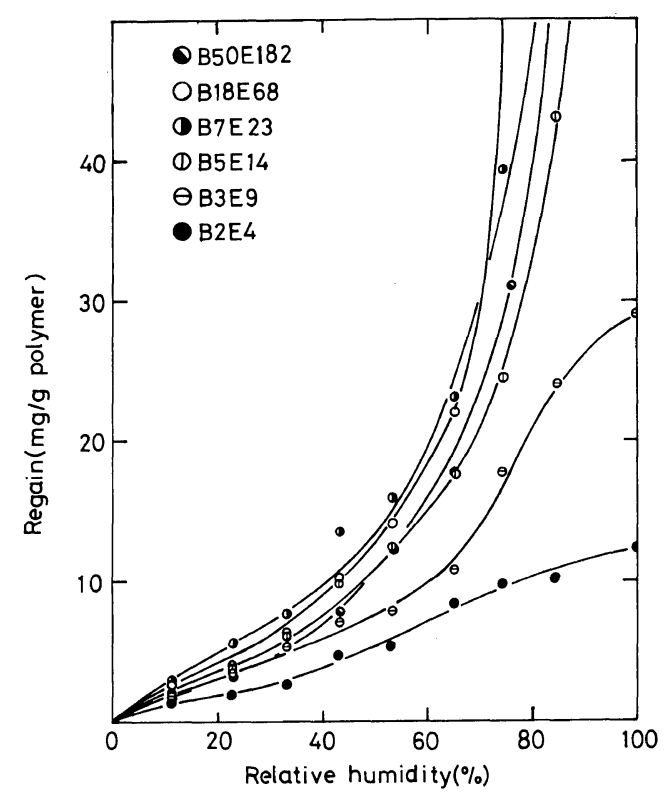

Figure 2. Equilibrium sorption isotherms for series II samples at $25^{\circ} \mathrm{C}$.

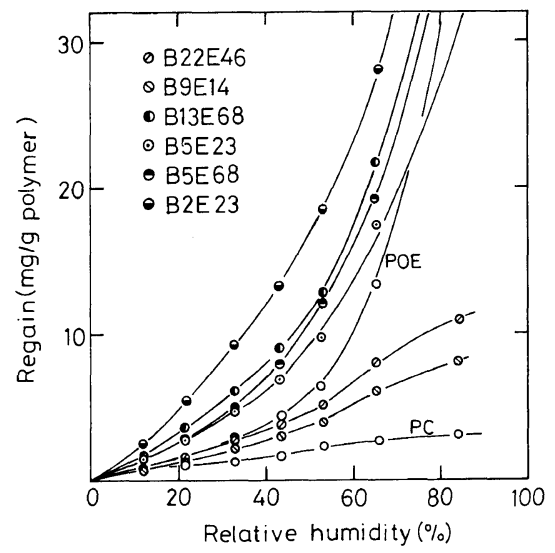

Figure 3. Equilibrium sorption isotherms for series III samples, homo-PC and $\mathrm{POE}$ at $25^{\circ} \mathrm{C}$.

the series II and III samples, along with those for homo-PC and POE. For the series II samples having a constant $\mathrm{PC} / \mathrm{POE}$ ratio (roughly 63/37) but increasing block length, the isotherm changes from the BrunauerEmmett-Teller (BET) ${ }^{22}$ type IV (or VI typical for nonwetting adsorbate/adsorbent systems ${ }^{23}$ ) to the BET type III. ${ }^{23}$ The former behavior can be seen often in hydrophobic homopolymers such as homo-PC, and the latter in hydrophilic homopolymers such as homo-POE. The isotherms for the series III samples with high PC content, such as B22E46 and B9E14, are of the BET type IV (or VI), and for the other series III samples with high POE content, of the BET type II (or III). At $25.0^{\circ} \mathrm{C}$, homo-POE is deliquescent beyond $80 \% \mathrm{RH}$, but not the copolymers even with high POE content. In the region of low $\mathrm{RH}$, the sorption capacity of the copolymers, except B22E46 and B9E14 with high PC content, is higher than that of homo-POE.

\section{Water Sorption Kinetics}

Figure 4 shows the reduced absorption curves for the series II samples at $\mathrm{RH}=$ $32.8 \%$. The absorption rate increases with increasing block length when the $\mathrm{PC} / \mathrm{POE}$ ratio remains constant. The reduced absorption curves for B50E182 and B18E68 are straight up to $60 \%$ of $C$. These are the so-called quasi-Fickian, while those for the other series II samples are non-Fickian.

Figure 5 shows the details of the reduced absorption and desorption curves for B50E182 at $\mathrm{RH}=32.8 \%$. It is evident that the desorption curve is always above the absorption curve, indicating that $D(C)$ decreases with increasing $C{ }^{1}{ }^{1}$ The other series II samples also showed behavior similar to that of B50E182.

Figure 6 shows the reduced absorption curves for homo-POE, series III long block samples, B5E68, B13E68, and B22E46, and homo-PC sample at $\mathrm{RH}=32.8 \%$. Among these samples, B13E68 with a 50/50 composition has the largest absorption rate. The curves for POE, B22E46 and PC (the curve a, $\mathrm{d}$, and e, respectively, in the figure) are nonFickian, while those for B13E68 and B5E16 with intermediate compositions (between $60 / 40$ to $30 / 70$ ) exhibit either Fickian or quasiFickian behavior. The copolymers usually had higher absorption rates than either homo-PC or POE. 


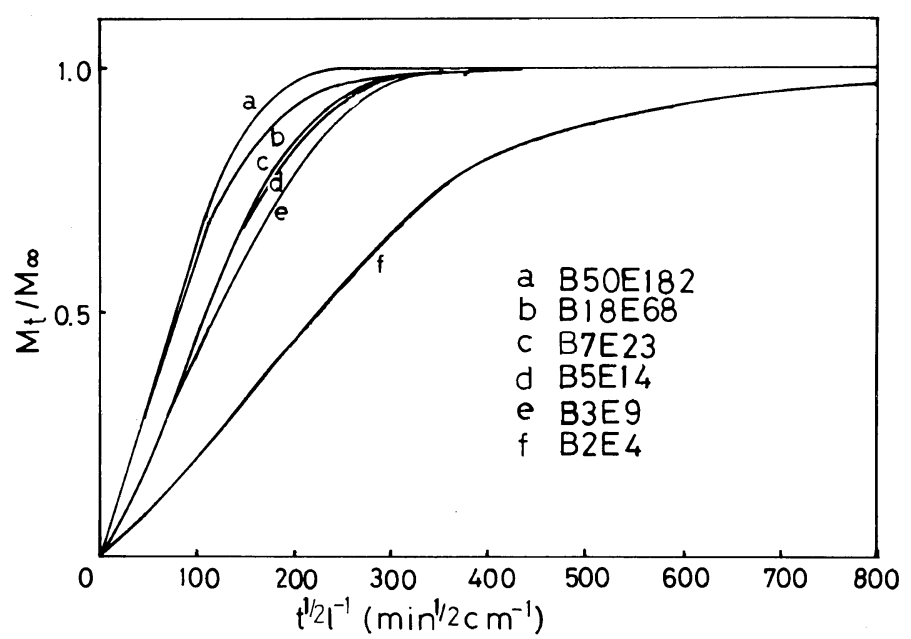

Figure 4. Reduced absorption curves for series II samples at $\mathrm{RH}=32 \%$ and $25^{\circ} \mathrm{C}$.

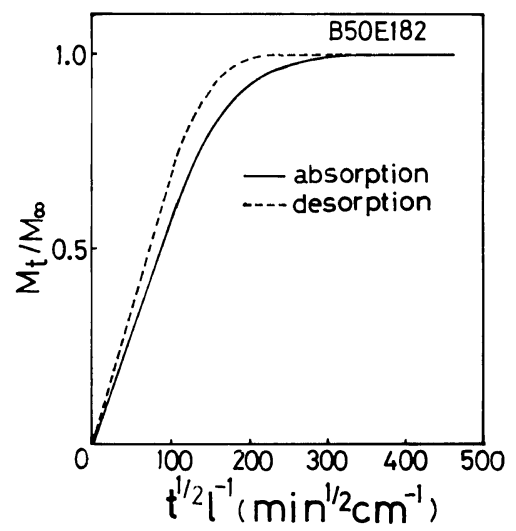

Figure 5. Reduced absorption and desorption curves for $\mathrm{B} 50 \mathrm{E} 182$ sample at $\mathrm{RH}=32 \%$ and $25^{\circ} \mathrm{C}$.

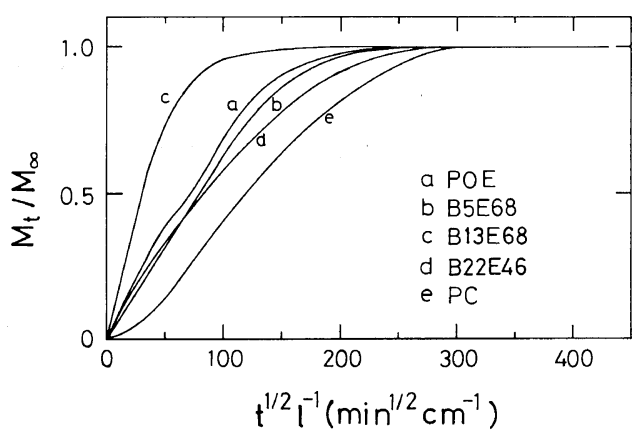

Figure 6. Reduced absorption curves for B5E68, $\mathrm{B} 13 \mathrm{E} 68, \mathrm{~B} 22 \mathrm{E} 46$, and homo-PC and $\mathrm{POE}$ at $\mathrm{RH}=32 \%$ and $25^{\circ} \mathrm{C}$.

\section{DISCUSSION}

\section{Water Sorption Capacity}

The findings described above indicate that the water sorption capacity of PC-POE copolymers depends on both PC/POE composition and block length. Figure 7 shows the amount of water absorbed (regain) plotted against the POE content for the series III samples at $\mathrm{RH}=32.8 \%$. The data for the homopolymers were estimated from those for homo-PC and POE under the assumption that only the amorphous regions of the homopolymers absorb water. The line joining the two homopolymer values represents the additivity of the sorption capacities of the PC and amorphous POE phases. It can be seen from the figure that additivity is roughly followed by these samples except B5E68.

We determined the degree of crystallinity $X_{\mathrm{c}}$ of the POE phase of the copolymer samples $^{18,19}$ by DSC and estimated their amorphous POE content. The results are shown in Table II. The high value of $X_{c}$ and thus the low value of the amorphous POE content (in spite of its high overall POE content) of the B5E68 sample may be responsible for its unusually low sorption capacity. Interestingly, above the POE crystalline melting temperature (about 


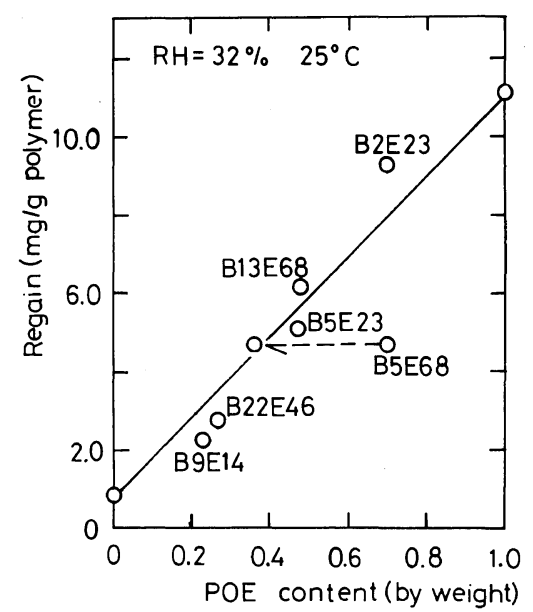

Figure 7. Plots of water regain vs. POE content for series III samples at $\mathrm{RH}=32 \%$ and $25^{\circ} \mathrm{C}$.

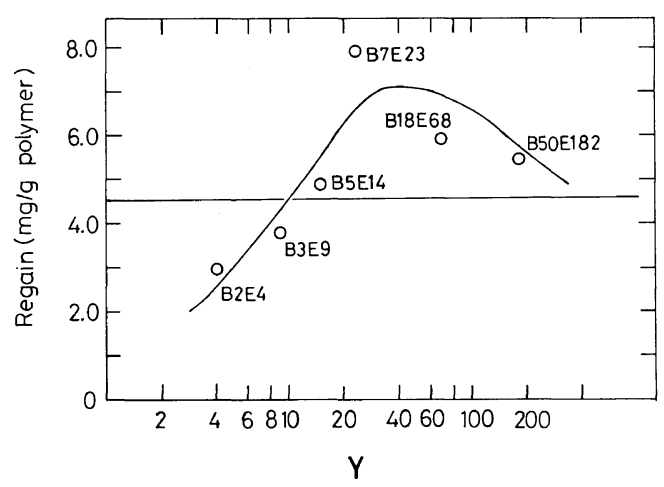

Figure 8. Plots of water regain vs. average POE block length $Y$ for series II samples at $\mathrm{RH}=32 \%$ and $25^{\circ} \mathrm{C}$.

$\left.50^{\circ} \mathrm{C}\right),{ }^{18,19}$ the sorption capacity of B5E68 is larger than that of B2E23.

The dependence of the water sorption capacity on block length is shown in Figure 8, by plotting the amount of water absorbed at $\mathrm{RH}=32.8 \%$ against the average POE block length $Y$ for the series II samples. The straight line indicates the additivity of the sorption capacity of the PC and amorphous POE phases (at $\mathrm{PC} / \mathrm{POE}=65 / 35$ ). The sorption capacity increases with increasing block length $Y$, exhibits a maximum in the range of $Y$ between 20 to 40 , and then decreases toward the additivity value with further increase in $Y$.
Our previous studies ${ }^{18,19}$ showed that microphase separation between PC and POE blocks is more complete in samples with longer blocks. This explains the block length dependence of the sorption capacity of these copolymers. However, it is interesting to note that the samples with blocks of intermediate length have a higher sorption capacity than those with longer blocks. This suggests that the interfacial regions, where PC and POE segments are mixed to some extent, may absorb more water than the pure POE phase.

\section{Analysis by the BET Theory}

To relate the PC/POE composition, block length, and water sorption capacity more quantitatively, we analyzed the sorption isotherms in terms of the BET theory. ${ }^{22,23}$ The BET equation reads

$$
\frac{P / P_{0}}{n\left(1-P / P_{0}\right)}=\frac{1}{K s}+\frac{(K-1) P / P_{0}}{K s}
$$

where $P / P_{0}$ is the relative humidity $\mathrm{RH}, n$ and $s$, the numbers of absorbed water molecules and active absorption sites per unit mass of the adsorbent, respectively, and $K$, the ratio of the internal partition functions for a water molecule bound in the first layer and that in the succeeding layers. If $K$ is larger than 1, the water molecule is more strongly bound by the absorption site rather than by other water molecules. In other words, the absorption sitewater interactions are stronger than the waterwater interactions. Thus, for large $K$, the BET equation reduces to the Langmuir equation for single layer adsorption. ${ }^{23,24}$ But in contrast, if $K$ is small, the BET type II isotherm is obtained, in which the isotherm is always downward convex toward the RH axis.

The BET equation is easy to apply and allows a reasonably consistent estimate of the $s$ value. ${ }^{23}$ However, a linear plot of $\left(P / P_{0}\right) /$ $n\left(1-P / P_{0}\right)$ vs. $P / P_{0}$ is usually limited to the region of $P / P_{0}(=\mathrm{RH})$ between 0.05 and 0.3 $(30 \%){ }^{23}$ From the plot in this region, we estimated $K$ and $s$ separately. Table II lists the 
results for the series II and III samples. For the series III samples except B5E68, the number of binding sites, $s$, varies in approximate proportion to the overall POE content. The low sorption capacity of B5E68 samples can be attributed to the small number of $s$ associated with a large crystallinity in the POE phase. For the series II samples, $s$ increased with increasing POE block length $Y$. This tendency reflects the fact that microphase separation becomes more complete and the pure POE domains become larger with increasing $Y$. On the other hand, among all the samples examined here, the parameter $K$ was the largest for B7E23 having blocks of intermediate length. Interestingly, this B7E23 sample exhibited the greatest sorption capacity. This may be due to the PC-POE intermixing phase which provides stronger binding sites for water molecules than the pure POE domains.

\section{Diffusion Kinetics and Rates}

From the reduced sorption curves in Figures 4 and 6, we see that the three samples B50E182, B18E69, and B13E68, having large $Y$, and two POE rich samples, B5E68 and B2E23, exhibit Fickian type behavior, while all others show non-Fickian behavior. It is known that the diffusion of small molecules in a rubbery polymer is usually Fickian, while that in a glassy polymer is non-Fickian. ${ }^{2}$ We have already reported ${ }^{18,19}$ that the glass transition temperatures $T_{\mathrm{g}}$ of the former five samples are close to that of homo-POE which is far below $25^{\circ} \mathrm{C}$, while those of the other samples are close to the $T_{\mathrm{g}}$ of the corresponding random copolymers which are well above $25^{\circ} \mathrm{C}$. These facts explain the difference in the sorption kinetics of these two groups of samples.

For the samples exhibiting Fickian or quasiFickian behavior, we estimated the average diffusion coefficient $\bar{D}$ by eq 1 and 2 . Figure 9 shows the $D$ estimated at $\mathrm{RH}=11.30 \%$ vs. the POE content for B50E182, B18E68, B13E68, and B2E23. The B5E58 sample has a relatively small $\bar{D}$, while the B13E68 sample, an ex-

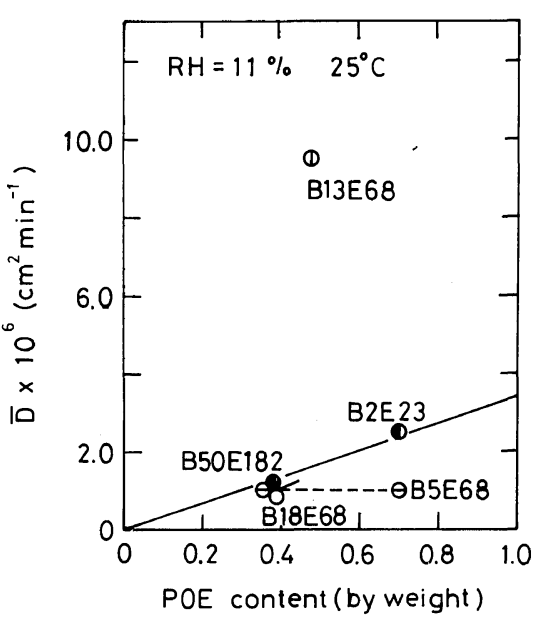

Figure 9. Plots of $\bar{D}$ vs. POE content for B50E182, B18E68, B13E68, B5E68, and B2E23 samples, all of which exhibit quasi-Fickian kinetics. The dashed arrow indicates the correction for the amorphous POE content.

tremely large $\bar{D}$. The $\bar{D}$ for the other samples increased in approximate proportion to POE content.

For semicrystalline polymers, the effects of the crystalline regions on the diffusion of gases and vapors have been discussed in terms of tortuosity or structural and chain immobilization factors. ${ }^{25,26}$ Thus, $D$ was expressed by

$$
D=D^{*} \tau^{-1} \beta^{-1}
$$

where $\tau$ is the tortuosity factor, $\beta$, the chain immobilization factor, and $D^{*}$, the value of $D$ at zero $\%$ crystallinity. The path for the diffusion of small molecules becomes zig-zag owing to the presence of impermeable or less permeable crystalline regions, and this gives rise to the tortuosity factor. The chain immobilization factor represents the restrictions of the mobility of amorphous chain segments by crystallites. ${ }^{25,26}$ Lasoski and Cobbs ${ }^{27}$ showed that $D$ for water in poly(ethylene terephthalate) is proportional to the amorphous content. Similar results have been reported for other semicrystalline polymer-gas systems. ${ }^{26}$

For the present BXEY copolymers, both hard PC domains and POE crystalline regions 
Water Sorption by PC-POE Multiblock Copolymers

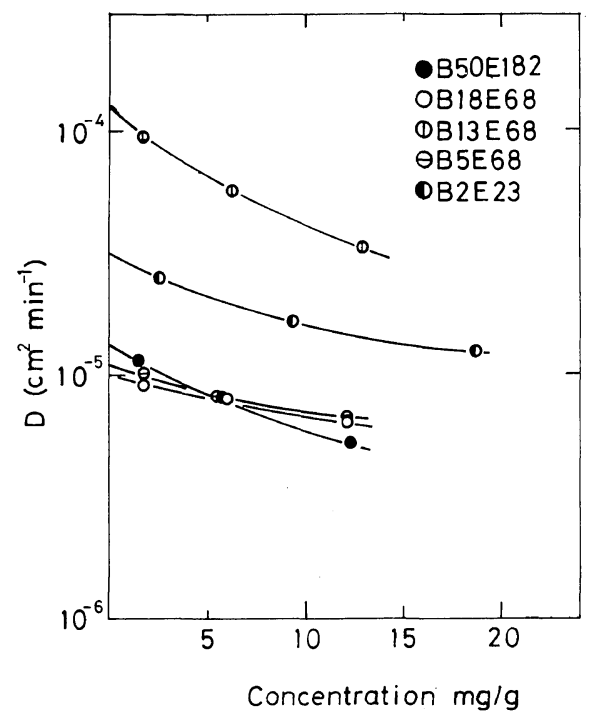

Figure 10. Concentration dependent diffusion. coefficient $D(C)$ for the five samples indicated in Figure 9.

should act as barriers for the diffusion of water. Thus, $\bar{D}$ is expected to be proportional to amorphous POE content rather than the overall POE content. The small $\bar{D}$ of the B5E68 sample may be explained by the fact that it has a rather high degree of crystallinity $(48 \%)$, while the POE domains of all other samples are nearly completely amorphous. In fact, if the $\bar{D}$ of this sample is replotted against its amorphous POE content, it falls on the line for other samples. The extremely large $\bar{D}$ of B13E68 sample may be due to the loose structure of the PC and POE intermixing regions. An adequate combination of block length and composition should thus provide a material which has a large $D$ as well as a large sorption capacity with the large affinity $K$ or $s$ toward water.

\section{Concentration Dependence of Diffusion Coef- ficient}

Figure 10 shows the concentration dependence of $D(C)$ determined for the five samples, B50E182, B18E68, B13E68, B5E68, and B2E23, which exhibited either Fickian or quasi-Fickian kinetics. It can be seen that $D$ is

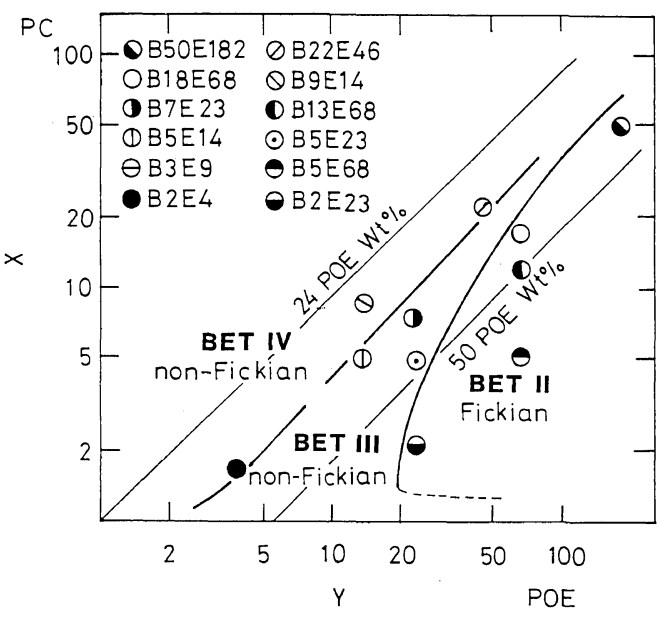

Figure 11. A block length $X v s$. $Y$ diagram classifying the sorption behavior of the BXEY samples at $25^{\circ} \mathrm{C}$.

a decreasing function of $C$. A decrease in $D$ with increasing $C$ was reported for the diffusion of water in less hydrophilic polymers such as poly(methyl methacrylate ${ }^{28,29}$ and ethylcellulose. ${ }^{30,31}$ This was explained by postulating the clustering of water molecules in the polymer matrix. The same mechanism may be responsible for the water sorption kinetics in the present systems.

\section{CONCLUSION}

The experimental results presented above show that the PC/POE ratio and block length strikingly influence the water sorption isotherm and kinetics of PC-POE multiblock copolymers. Figure 11 schematically summarizes the observed sorption behavior, which may be classified as three types. High PC content and/or short block samples, B2E4, $\mathrm{B} 9 \mathrm{E} 14$, and B22E46 may be classified as the first group exhibiting a BET type IV isotherm and non-Fickian kinetics. Because these samples have a PC-rich continuous phase, their sorption behavior resembles that of PC homopolymer. Samples of intermediate composition and block length, B3E9, B5E14, B7E23, and B5E23, belong to the second type exhibiting a 
BET type III isotherm and non-Fickian kinetics. In these samples, microphase separation occurs less completely and the glassy PC-POE intermixing domains dominate, so that the samples exhibit non-Fickian behavior. High POE content and/or relatively long POE block samples, B2E23, B5E68, B13E68, $\mathrm{B} 18 \mathrm{E} 68$, and B50E182, belong to the third type exhibiting a BET type II isotherm and Fickian behavior. This behavior cannont be found in crystallizable POE nor PC homopolymers. In the third group samples, numerous amorphous POE domains produced as a result of the conformational constraint of the hard PC blocks may be responsible for this peculiar sorption behavior.

Acknowledgement. The work was supported by the Ministry of Education, Science, and Culture (Mombusho) under Grants 543026 (to TK) and 58350053 (to Professor Kurata, Kyoto University, the coordinator of the research program), which are gratefully acknowledged.

\section{REFERENCES}

1. H. Fujita, Fortchr. Hochpolym. Forsch. (Adv. Polym. Sci.), 3, 1 (1960).

2. J. Crank and G. S. Park (Ed.), "Diffusion in Polymers," Academic Press, London and New York, 1968.

3. J. Crank, "The Mathematics of Diffusion," 2nd Ed., Clarendon Press, Oxford, 1975.

4. V. T. Stannett, H. B. Hopfenberg, and J. L. Williams, Polym. Sci. Technol., 1, 321 (1973).

5. J. A. Barrie, "Diffusion in Polymers," J. Crank and G. S. Park, Ed., Academic Press, London and New York, 1968, Chapter 8.

6. J. A. Barrie and D. J. Marchin, J. Macromol. Sci.,
B3, 645 (1969).

7. J. L. Williams, H. B. Hopfenberg, and V. T. Stannett, J. Macromol. Sci., B3, 711 (1969).

8. N. G. Spencer and S. C. Honeycutt, J. Polym. Sci., Polym. Symp., 41, 129 (1973).

9. G. W. C. Hung, J. Macromol. Sci., A9, 211 (1975).

10. I. C. Watt, Text. Res. J., 30, 644 (1960).

11. T. Asada and S. Onogi, J. Colloid Sci., 18, 784 (1963).

12. T. Asada, K. Inoue, and S. Onogi, Polym. J., 8, 21 (1975).

13. A. W. Mayers, J. A. Myer, C. E. Rogers, V. T. Stannett, and M. Szwarc, Tappi, 44, 1961 (1961).

14. H. Odani, Nihonreorojigakkaishi, 8, 89 (1980).

15. M. Shen and H. Kawai, AIChE J., 24, 1 (1978).

16. T. Kotaka and M. Shen (Ed.), "Proceedings of USJapan Joint Seminar on Multicomponent Polymers (J. Macromol. Sci., Phys., B17, Nos. 2-4), Marcel Dekker, New York, 1980.

17. T. Kotaka, F. Ide, K. Ogino, and T. Nishi (Ed.), "Porima Aroi (Polymer Alloys)," Tokyo Kagakudojin, Tokyo, 1981.

18. T. Suzuki and T. Kotaka, Macromolecules, 13, 1961 (1980).

19. T. Suzuki and T. Kotaka, Polym. J., 15, 15 (1983).

20. E. P. Goldberg, J. Polym. Sci., C4, 707 (1977).

21. L. J. Greenspan, J. Res. Nat. Bur. Stand., 81A, 89 (1977).

22. S. Braunauer, P. H. Emmett, and E. T. Teller, J. Am. Chem. Soc., 67, 309 (1983).

23. A. W. Adamson, "Physical Properties of Surfaces," 4th Ed., John Wiley, New York, 1982, Chapter XVI.

24. I. Langmuir, J. Am. Chem. Soc., 40, 1361 (1918).

25. A. Michaels, W. Vieth, and J. J. Barrie, J. Appl. Phys., 34, 13 (1963).

26. H. B. Hopfenberg and V. T. Stannett, "The Physics of Glassy Polymers,” R. N. Haward, Ed., Appl. Sci. Publishers, London, 1973, Chapter 9.

27. S. W. Lasoski and W. H. Cobbs, J. Polym. Sci., 36, 21 (1959).

28. J. A. Barrie and B. Platt, Polymer, 4, 303 (1963).

29. M. Braden, Mod. Plastics, 40, 83 (1963).

30. H. Yasuda and V. T. Stannett, J. Polym. Sci., 57, 907 (1962).

31. J. D. Wellons and V. T. Stannett, J. Polym. Sci., A-1, 4, 593 (1966). 